\title{
Family Resilience in the Field of Nursing: Concept Analysis
}

\author{
1st Abdul Wakhid \\ Faculty of Nursing \\ Universitas Ngudi Waluyo \\ Semarang, IndonesiaEmail: \\ abdul.wakhid2010@gmail.com
}

\author{
2nd Achir Yani S. Hamid \\ Faculty of Nursing \\ Universitas Indonesia \\ Jakarta, Indonesia \\ Email: ayanihamid@yahoo.co.id
}

\author{
3rd Mustikasari \\ Faculty of Nursing \\ Universitas Indonesia \\ Jakarta, Indonesia \\ Email: titiayu.titi@gmail.com
}

\begin{abstract}
Family resilience is established to reduce the incidence of trauma, depression, loss and crisis experienced by families and family members. Apart from the importance of the concept of family resilience, there has not been an adequate focus on all aspects of this concept in the discipline of nursing.

Objective: This paper reports an analysis of the concept of family resilience. Methods: This concept analysis approach applies the theories of Walker and Avant. Results: Family resilience attributes include (1) ability to absorb (2) adaptability (3) ability to change (4) welfare promotion (5) achieve function (6) empower resources in the family. These attributes are ability to learn from experience, adaptability, ability to function again, ability to overcome crises, ability to recover, and empower resources in the family.

Conclusion: building family resilience in preventing postdisaster psychosocial problems is the main goal of disaster management on a psychosocial perspective. This analysis provides a new perspective for nurses by helping them understand all components in the concept of family resilience.
\end{abstract}

Keywords: concept analysis, family resilience, nursing

\section{INTRODUCTION}

The family resilience approach is built to develop and strengthen family capacity to overcome difficulties [1]. In Indonesia, post-disaster family resilience in preventing psychosocial problems has not received much attention from various groups. Building family resilience is in fact a real effort to build family capacity to survive, adapt and fight stress by using resources within the family itself. Family resilience is built to reduce the incidence of depression, loss and crisis experienced by families and family members. Apart from the importance of the concept of family resilience, there has not been an adequate focus on all aspects of this concept in the discipline of nursing. Furthermore, other researchers provide different definitions. The purpose of this concept analysis is to uphold the concept of family resilience which is still ambiguous and determines the specific meaning of family resilience.

The term family resilience is often used in various health studies. As stated by [2] using the term family resilience namely positive adjustment with higher levels of spirituality, higher levels of life satisfaction, and lower levels of depression correlated significantly. Furthermore, Feder, et al. [3] use family resilience as the ability to withstand difficulties or, more specifically, the ability to maintain an allostatic mechanism in the presence of stressors. As a matter of fact, [4-6] using family resilience in the context of family overcomes difficulties, while others with similar situations do not have the same response. Concept analysis identifies the unique characteristics of each concept and provides an appropriate operational definition of the concept. In addition, concept analysis can improve ambiguous concepts in theory. This can then provide a more basic and deeper understanding of the attributes underlying the concept [7]. In this paper, to test the concept of family resilience related to nursing, we employed eight steps of the process, i.e. (1) choosing a concept (2) determining the purpose of the analysis (3) identifying all conceptual uses (4) defining attributes (5) building case models (6) identifying antecedents (7) identifying consequences and (8) determining empirical references [7].

\section{Methodology}

The study was conducted by examining the research literature using keywords; "Family resilience" and "Family hardiness". The identification of the concept of toughness was done by searching literature on 896 articles in the database Science Direct, Proquest, Wiley Online Library, Springer Link, and Ebscohost. Literature search results can be divided into a number of source classifications, namely dictionaries and literature (nursing). Literary inclusion criteria include as follows: Article title containing keywords, in the form of journal articles, written in English, publication between January 2015-October 2018. Articles that met the criteria of 18 articles were analysed, after screening by title, abstract, and eligibility.

\section{RESULTS}

\section{THE THEORETICAL FRAMEWORK OF FAMILY RESILIENCE}

Family resilience does not appear in the dictionary as a whole term. However, "toughness" and "family" can be found separately. First, according to online KBBI, resilience is "tenacity, strength" [8]. According to dictionary.com/browse/ [9] toughness is "the strength or ability to return to its original shape, position, after being bent, pressed, or stretched; elasticity. The English-Oxford dictionary describes resilience as the capacity to recover quickly from difficulties; violence [10]

Second, according to online KBBI, the family is "mother and father and their children; whole house [8]. According to dictionary.com/browse/ [9] the family is a basic social unit consisting of parents and their children, considered to be a group, whether living together or not. Besides, according to the oxfordEnglish family the dictionary is "a group consisting of two parents and their children living together as a whole" [10]. 
Apart from dictionary definitions, the term family resilience appears in the field of health/nursing [11] defines family resilience as a predictor or independent variable given that as a social construct it is significantly related to the psychological well-being of family members. define family resilience as the family's ability to restore and maintain its collective integrity while promoting the well-being of every family member and family as a whole [12]. Family resilience is that ability which does not only involve more than being able to manage and survive stressful events but also uses the difficulty to forge personal growth and transformative relationships [1]. In addition, family resilience is defined as a person's ability to cope with or adapt to stress hazards starting from the level of preparation for potential hazards, and prior planned adjustments in response to perceived hazards, including relief and rescue [13].

2. Attributes or characteristics of family resilience Attributes as characteristics that appear in a concept repeatedly and help researchers distinguish the occurrence of a specific phenomenon from the same [7]. This review of the literature helps to identify the characteristics of family resilience that are influenced by family abilities. These characteristics can be summarized into ability to learn from experience, adaptability, ability to function again, ability to overcome crises, ability to recover, and empower resources in the family.

Operational definition: Family resilience is the family's ability to adapt to change, recovering from its original function through learning from experience by empowering resources in the family.

Stages in the concept of analysis [7] include:

1.1. Choose a concept, beginning with the selection of a phenomenon and giving a label.

Concept: toughness

Mr. Pamuji's family has 2 teenagers; he works as farmer every day and serves as a village chief. In 2010, Mr. Pamuji's family suffered a catastrophic eruption of Mount Merapi, which was the 12th eruption experienced by Mr. Pamuji all this time. During this time Mr. Pamuji's family has never received assistance/explanation / health education on ways to deal with the catastrophic eruption of Mount Merapi. In 2011, Mr Pamuji's village arrived by a group of nursing students who practiced in the area of Mr. Pamuji's Village. As long as students are there, students carry out various activities starting from the assessment of mental health problems that arise in each family, determine the problems experienced, determine the intervention, train the family to solve the problems faced and evaluate the results of activities.

The results of the evaluation of the student practice activities found that the family of $\mathrm{Mr}$. Pamuji and several other families stated that they were ready and brave to face the next disaster because they already had knowledge about how to deal with disasters to prevent psychosocial problems that arise. Mr. Pamuji's family is a family that is actively involved in community capacity building activities in the face of disasters, the family feels helped by the assistance activities, families are able to detect psychological problems due to disasters, and the family spends a lot of time and energy studying disaster preparedness.

Based on some of the found phenomena, the authors label that families have resilience to prevent psychosocial problems that occur due to disasters.

1.2. Determine the objectives of analysing the concept of Resilience are:

a. Uphold the concept of resilience which is still ambiguous

b. To determine the specific meaning of toughness

c. To determine the belief in the concept of family resilience in playing an active role in preventing psychosocial problems due to disasters.

1.3. Identify all uses of the selected concept.

The identification of the concept of resilience is done by searching the literature on 896 articles in the Science Direct, Proquest, Wiley Online Library, Springer Link, and Ebscohost databases. The results of search literature are divided into several classifications of sources, namely dictionaries and literature (nursing).

Sources from dictionaries are obtained as follows: Resilience is tenacity, strength [8]. Ecology: The capacity of an ecosystem to recover from interference [14]. Social: the ability of a system to withstand changes in its environment and still function [14]. Psychological resilience is the ability to overcome crises or to return to pre-crisis status quickly [14]. Psychological resilience is in people who develop psychological abilities and behaviours that allow them to remain calm during crises / chaos and to move away from incidents without long-term negative consequences. [14]. Material: the ability of a material to absorb energy when defective, and release that energy when dismantled [14]. Strength or ability to return to the original form, position, etc., after being bent, compressed, or stretched; elasticity [9].

The family's ability to restore and maintain its collective integrity while promoting welfare [12]. The body's tense ability to restore its size and shape after deformation caused primarily by pressure [15]. Resilience is it involves more than being able to manage and endure stressful events but also uses the difficulty to forge transformative personals and relationship growth [1]. A person's ability to cope with or adapt to the dangers of stress starts from the level of preparation for potential hazards, and planned adjustments in response to perceived hazards, including 
assistance and rescue [13]. Sustainability 'function, structure, and identity in a way that highlights' keeping the way of life' after an emergency [16]. The ability to adapt to change, to adjust its structure, modify or change in changing circumstances [17]. As a system that is able to absorb, adapt, transform and prepare for past and future impacts from economic, environmental and social shocks or pressures, in order to promote sustainable development, prosperity and maintain acceptable growth patterns [18]. Family and Community Resilience; a resilience-oriented practice approach recognizes the broad impact of major trauma, places distress in extreme experience, attends ripple effects through relational networks, and aims to strengthen family and community resources for optimal recovery [19]. Family resilience: the ability to maintain, or reach a level of function that is competent in one or more domain functions (i.e., cohesion, adaptation, communication) [20].

Operational definition: Family resilience is the ability of the family to learn from trauma experience to recover and to its original function by empowering resources in the family.

1.4. Determine the selected attribute.
a. Ability to absorb
b. Adaptability
c. Ability to change
d. Ability to overcome crises
e. Ability to recover
f. Empower resources in the family

1.5. Make a case model: create / compose a scenario whose contents include attributes that have been identified in the previous stage.

Sample case:

A family has experience of displacement during the 2010 Mount Merapi eruption, the family has identified that the 5-year cycle of the eruption of Mount Merapi. Since the eruption in 2010, the family has chosen to take part in the activity to recognize the psychological impact that has occurred on family members due to the Merapi eruption. The family has recognized the psychological consequences thanks to the existence of a healthy alert village program that was formed. At present the family is no longer worried if one day the eruption of Mount Merapi occurs again, because it already has a good understanding of how to prevent the psychological impact that might occur. Families have the confidence to be able to survive and deal with disasters well. Families are actively involved in stress recognition programs and psychological impacts that can occur.

Create a borderline case ( 3 of 4 features), and a contradictory case (an illustration that is not included, either in whole or in part)

Borderline case caring:

Families who have family members with mental disorders who have been hospitalized 3 times, bring their family members to the hospital when they experience signs and symptoms of recurrence. The family recognizes the signs and symptoms of relapse of mental disorders, the family is able to give medication to patients, the family is able to train activities to patients to control their mental disorders. The family experiences fear if suddenly the client leaves the house and violence.

Examples of contrary cases:

A man, 50 years of having hypertension, the client does not recognize the signs and symptoms of hypertension because he had never before experienced hypertension. Clients do not know the diet of hypertensive patients, clients do not know the limits of activities that can be done in hypertensive patients, and clients do not routinely take medication.

1.6. Identify something that precedes before the chosen concept (likely to be a confounding factor) and something that becomes a result of a chosen concept (the impact of the concept). The precedes before concept is called antecedence, consisting of Crisis [1, 12, 21], learning from experience [13], Disaster, Damage, Loss [16], Exposure to danger [22], Support, Communication [23]. Chosen concept in this study is family resilience. And the precedes after concept is called consequence, consist are: Positive belief [21], Protect the health [13], family resilience planning and programs [16], established coping capacities [22], Cohesion [23].

\subsection{Defined empirical referent}

Empirical referents from family resilience are; ability to absorb, adaptability, ability to survive, ability to overcome crises, reach function, and empower resources in the family. Once empirical referents are identified, CAN be part of the measuring tool.

\section{Conclusion}

Family resilience is the ability to absorb, adapt positively, change stressful events, promote well-being to achieve one or more original functions by empowering resources in the family. Family resilience attributes consist of ability to absorb, adaptability, ability to change, promotion of well-being, achieving family functions and empowering resources in the family.

[1] F. Walsh, "A family resilience frameworkInnovative practice applications," ProQuest, vol. 51, no. 2, p. 130, 2002.

[2] B. White, S. Driver, and A. M. Warren, "Resilience and indicators of adjustment during rehabilitation from a spinal cord injury," Rehabilitation psychology, vol. 55, no. 1, p. 23, 2010. 
[3] A. Feder, E. J. Nestler, and D. S. Charney, "Psychobiology and molecular genetics of resilience," Nature Reviews Neuroscience, vol. 10, no. $6, \quad$ pp. 446-457, 2009.https://dx.doi.org/10.1038/nrn2649

[4] D. McConnell and A. Savage, "Stress and resilience among families caring for children with intellectual disability: expanding the research agenda," Current developmental disorders reports, vol. 2, no. 2, pp. 100-109, 2015.

[5] D. McConnell, A. Savage, and R. Breitkreuz, "Resilience in families raising children with disabilities and behavior problems," Research in developmental disabilities, vol. 35, no. 4, pp. 833848, 2014.

[6] J. W. Peer and S. B. Hillman, "Stress and resilience for parents of children with intellectual and developmental disabilities: A review of key factors and recommendations for practitioners," Journal of Policy and Practice in Intellectual Disabilities, vol. 11, no. 2, pp. 92-98, 2014.

[7] L. O. Walker and K. C. Avant, Strategies for Theory Construction in Nursing, Fifth Edition ed. United State of America: Pearson Education Inc., 2011.

[8] kbbi.kata.web.id, "KBBI.kata.web," 2019.

[9] dictionary.com/browse/, "https://www.dictionary.com/browse/resilience," 2019.

[10] en.oxforddictionaries.com/definition/, "https://en.oxforddictionaries.com/definition/resilien ce," 2019.

[11] D. Baumrind, The Jossey-Bass social and behavioral science series: Child development today and tomorrow. San Francisco, CA, US: Jossey-Bass, 1989.

[12] M. McCubbin, I. McCubbin, and A. Thompson, "Family hardiness index. En J. Fischer \& K Corcoran," Measures for clinical practice: A sourcebook, pp. 286-288, 1994.

[13] R. A. Cash et al., "Reducing the health effect of natural hazards in Bangladesh," The Lancet, vol. 382, no. 9910, pp. 2094-2103, 2013/12/21/ 2013.https://doi.org/10.1016/S0140-6736(13)619480

[14] en.wikipedia.org/wiki/, "https://en.wikipedia.org/wiki/Resilience," 2019.

[15] M. T. Sixbey, "Development of the Family Resilience Assessment Scale to identify family resilience constructs," 3204501 Ph.D., University of Florida, Ann Arbor, 2005.

[16] J. Adekola, "Resilience from a lived-experience perspective in the regional context of Dumfries and Galloway, Scotland," International Journal of Disaster Risk Reduction, vol. 31, pp. 441-448, 2018/10/01/

2018.https://doi.org/10.1016/j.ijdrr.2018.06.006

[17] R. Martin, "Regional economic resilience, hysteresis and recessionary shocks," Journal of economic geography, vol. 12, no. 1, pp. 1-32, 2011.

[18] K. Borsekova, P. Nijkamp, and P. Guevara, "Urban resilience patterns after an external shock: An exploratory study," International Journal of Disaster
Risk Reduction, vol. 31, pp. 381-392, 2018/10/01/ 2018.https://doi.org/10.1016/j.ijdrr.2018.05.012

[19] F. Walsh, "Traumatic loss and major disasters: Strengthening family and community resilience," Family process, vol. 46, no. 2, pp. 207-227, 2007.

[20] M. Van Schoors, L. Caes, L. L. Verhofstadt, L. Goubert, and M. A. Alderfer, "Systematic review: Family resilience after pediatric cancer diagnosis," Journal of Pediatric Psychology, vol. 40, no. 9, pp. 856-868, 2015.

[21] K. Glonti et al., "A Systematic Review on Health Resilience to Economic Crises," (in English), PLoS One, vol. 10, no. 4, Apr 2015; 2017-12-30 2015.http://dx.doi.org/10.1371/journal.pone.0123117

[22] A. Chacowry, L. J. McEwen, and K. Lynch, "Recovery and resilience of communities in flood risk zones in a small island developing state: A case study from a suburban settlement of Port Louis, Mauritius," International Journal of Disaster Risk Reduction, vol. 28, pp. 826-838, 2018/06/01/ 2018.https://doi.org/10.1016/j.ijdrr.2018.03.019

[23] D. H. Olson, "Circumplex Model of Marital and Family Systems," Journal of Family Therapy, vol. 22, pp. 144-167, 2000.https://doi.org/10.1111/14676427.00144

[24] B. Biscoe and B. Harris, "RAS Resilience Attitudes Scale Manuel (adolescent version)," Oklahoma City: Eagle Ridge Institute, 1994.

[25] D. H. Olson, R. Bell, and J. Portner, "Family adaptability and cohesion evaluation scales," FACES-II, Family Inventories Manual Life Innovations, Minneapolis, MN, 1992. 